\title{
A Study on Airline E-Ticketing System in Malaysia Among Malaysia and Non-Malaysia Customers
}

\author{
*Nor Alina Ismail, Siti Norbaya Daud, Nor Anis Asma Sulaiman \\ School of Information Technology, SEGi University
}

*noralinaismail@segi.edu.my

\begin{abstract}
During the past ten years the impact of the internet on channel selection has been dramatic and pervasive throughout the business world. Yet strong arguments can be made that few industries have been as invasively affected as has the airlines industry. Currently travellers increasingly choose the websites to search for flight ticket or other things. This paper provides a report of a study that investigated customers' perception towards purchase flight ticket online as well as why some people choose to use this facility and why some other still stick with the traditional method of buying flight ticket online. Hence, the three factors of online buying were examined in this study.
\end{abstract}

Keywords: Airline Industry, e-ticketing system, e-service, e-transaction, Air Asi

\section{Introduction}

Generally, online shopping involves seeking information and carrying out activities that provide the customers the information that help them to arrive at an informed decision and conduct business. On the other hand, online buying represents technological infrastructure used to exchange data and purchase product or services electronically (Ainin et al, 2009). The airline industry has been a major beneficiary of this phenomenon as seen in the growth recorded in the emergence of travelling agencies within a very short time of period. Most of these agencies within the last decade have set up website and mobile applications to communicate and remove the barrier to reach to their customer and target market but there are still a lot of people who stick to the traditional way of purchasing tickets because of so many factors. 
Some of the users find this approach quite risky, or they may not be able to use the internet well, on the other hands, they may not be skilful enough and this is where dexterity at the use of computer system plays a significant role in influencing the user (Carla et al., 2009). The growing use of Information Technology (IT) in airlines industry revolutionized the interaction between company and customers and can increasingly standardized many services in airlines companies. For example, in this technology era, customers are able to: (a) search information, (b) booking or purchasing flight ticket, (c) loyalty program and many other features through website at anytime and anywhere in the world (Rafidah, 2014).

The purpose of this paper is to explore and understand the study on Air Asia e-ticketing system especially on the e-transaction cycle as now eticketing is become more popular electronic transaction among airlines companies globally.

\section{Literature Review}

Over the past decade, the growth of computer-related technologies and the wider acceptance of the Internet led to changes in internet user behaviours. Besides, e-commerce has increased highly in order to develop a new marketplace for many industries, such as travel and tourism, entertainment, hotel, transportation, and also airline industry (June \& Meiga, 2012). Thus, eticketing has been considered as an important contribution in the e-Commerce field. Hence, according to ebookers.com (2015), e-ticket is a technology that is paperless and time-saving to various types of activities, such as amusement, travel, and many more. E-ticketing, in general, is a new way to buy a ticket using Internet application. This process involves two main parties between company and customer. This technology allows customers not only limited to buy a ticket, but allows customers to compare price, products, and other eservice facilities before they decide to make a purchase.

Based on Malaysia Internet User record, in 2011, about $65 \%$ of electronic buyers bought airline tickets online. This system has offered numerous benefits to customers, including decision-making before make a purchase 
(Sulaiman et.al, 2008). The past studies concluded that an airline e-ticketing system is not a new services provided to customer especially in Malaysia scenario. Hence, the e-ticketing services is not really new among customer nowadays because more than half customers have been purchase flight ticket using system for the last two decade. According to Sulaiman et.al (2006, 2008), the pioneer of e-ticketing system is AirAsia Berhad in 2005. This statement is also agreed Rafidah (2014). The AirAsia Company is also known as the low-cost carrier airline in Malaysia. In fact, a high percentage of customers in Malaysia buys flight ticket rather than other types of tickets, such as entertainment, cinema, and sports. Perhaps, due to successful sales and promotion done by airlines in Malaysia, awareness among customers can be developed (Rafidah, 2014). Moreover, the airline e-ticketing system implemented by many airline companies in Malaysia, such as Malaysia airlines, AirAsia, Malindo, MasWing, and Firefly, and offering a low fare system.

\subsection{E-ticketing System}

In year of 2003 Will (2016) found that the US airline industry had lost over 15 billion since the tragedy in September 2001 and was expected to lose another 5 billion in year 2005. Moreover, many airlines companies was attempted to improve their business and minimize loses by implementing a web based or mobile application. Based on world report, most succeed approached by implemented e-ticketing system and this system normally acts like an alternative system to sell their product through internet by using website. This strategy to ensure can increase customers' satisfaction.

E-ticketing can be defined as a model that allows approved agents to transmit ticketing information directly to database and all the details of customer will store in database. This means all the transaction will do electronically using website and customer will give a unique code (booking number / flight number) via internet like e-mail or over the phone if any (Randiwela, 2010). Through the expanded use of e-ticketing system, airlines are able to reduce labour costs and in some cases eliminate commissions 
altogether so as to improve profit margins. An airline e-ticket is used to represent the purchase of a seat on a customer airline, usually through a website. An airline e-ticket combines the issue and delivery of the ticket into a single operation which is a more practical and faster option to conventional manual airline ticketing, effecting sizeable savings for both airlines and travel agent (Will, 2016).

E-Ticketing is not only available on web-based system. Customers also can buy using phone application, electronic kiosk and more (June \& Meiga, 2012). For example, recently, many customers tend to purchase cinema tickets using mobile application or website rather than queuing at the counter. This activity is part of pre-purchase in transaction cycle where customers perform prior to place an order (Alhiou, 2011; Lu \& Fienberg, 2003; Khalifa \& Shen, 2005). According to Romano et al (2013), e-ticketing is gaining popularity vastly compared to other online shopping because can give many benefits to both company and customer. One of the benefits is its can reduce cost in term of printing a paper ticket at once can save time of both side. Other benefits can get by buying online ticket is customers can feel more convince because they no need to carry a paper ticket because recently airlines companies allowed their customers to check-in online over website and can choose their favourite seats. The long term relationship provides many potential benefits for many service companies in various industries especially in airline industry.

\subsection{Research Design}

Research design is one of the important elements in a research because it is a strategy for answering the questions and making a hypothesis testing that stimulate the research in the first place. The purpose of the research design implemented in this study was to review some of the research designs that were used in the past Information System (IS) studies, followed by a discussion of the rationale for a particular design. The research design was based on a research model and it helped to align the planned methodology with the research problem. This research design also helped to draw 
boundaries for the research in defining the study setting, the type of investigation that had to be carried out, the unit of analysis, and other relevant issues related to research process, which would only succeed if the researcher made the right choices in the research design (Duffy, 1985).

In this study, the focus group interview session has been conducted in order to help a researcher to collect a data and also to develop and instrument.

\subsection{Instrument and Data Collection}

The chosen method for the data collection is focus group. Focus group also give benefits because they allow participants or interviewees to feed of one another's ideas and spark thoughts that may not have been captured in isolation. The focus group session was conducted as a step to get better understanding of flight e-ticketing system in Malaysia. The researcher used this approach to identify customers' perspective towards airline e-ticketing system.

\subsection{Sample of the Study}

The focus group was successfully conducted on July 2013, involving eight participants of postgraduate students in Kuliyyah of Information and Communication Technology (KICT) from the International Islamic University Malaysia (IIUM). The participants were selected based on two main criteria which is first must be experienced in using any airlines (MAS, AirAsia, Firefly, Malindo, or MASwings) and e-ticketing system in Malaysia, and secondly is Malaysian and non-Malaysian. The open-ended question method was used for this focus group session discussion

\section{Data Analysis}

The descriptive of this focus group as depicted in Table 1 while the questions of this data collection depicted in Table 2 below: 
Table 1. Profile of respondents for pre-instrument development

\begin{tabular}{|l|c|}
\hline \multicolumn{1}{|c|}{ Characteristic } & Frequency (N) \\
\hline Gender: & 3 \\
Male & 5 \\
Female & \\
\hline Age: & 4 \\
25 to 34 years & 4 \\
35 to 44 years & \\
\hline Race: & 4 \\
Malay & 4 \\
Non-malaysian & \\
\hline Employment Status: & 2 \\
Employed & 6 \\
Un-employed & \\
\hline Marital Status: & 2 \\
Single & 6 \\
Married & \\
\hline Highest education: & 8 \\
Post-graduate / professional certificate & \\
\hline
\end{tabular}

Table 2. The questions

\begin{tabular}{|l|l|}
\hline No. & \multicolumn{1}{c|}{ Question. } \\
\hline 1. & $\begin{array}{l}\text { - Do you normally buy a ticket from the same airline? } \\
\text { - What factors those lead you to buy a ticket from the same airline? }\end{array}$ \\
\hline 2. & $\begin{array}{l}\text { - How would you describe your experience on the website? } \\
\text { - What are the common functions on the web that you normally do? } \\
\text { - Which one of these functions is problematic or not meeting your } \\
\text { expectation? }\end{array}$ \\
\hline 3. & $\begin{array}{l}\text { - Do you have an experience using holiday package on website? } \\
\text { - In term of holiday needs, what your expectation on this? }\end{array}$ \\
\hline 4. & - Would you trust this system? \\
\hline 5. & $\begin{array}{l}\text { - What other things (besides web) that will make your online experience } \\
\text { better? }\end{array}$ \\
\hline 6. & $\begin{array}{l}\text { - Is there any cultural or religion issues that affect your satisfaction towards } \\
\text { airlines e-ticketing services? } \\
\text { - Any other bad experience with other e-ticketing system? }\end{array}$ \\
\hline 7. & $\begin{array}{l}\text { - What are your expectations on improvement for airlines e-ticketing } \\
\text { websites in Malaysia? Perhaps available on the other airlines sites but not in } \\
\text { Malaysia websites? }\end{array}$ \\
\hline
\end{tabular}

\section{Results and Discussion}

During the discussion, all the participants were asked to comment on how satisfied they were using any services provided by any airlines in Malaysia. The services including web design, search capabilities such as searching on 
ticket prices, payment methods, check-in options, holiday package as well as all the other features on websites.

Most of the participants were not satisfied and expressed mild frustration with AirAsia Berhad in terms of hidden charges, web check-in services, culture of flight attendants, the interface of the websites, and most of them tried to make comparisons with other airlines. Nevertheless, only one respondent who was satisfied with the overall services of the AirAsia Berhad system because she found that only this airline provided direct debit as an epayment method during that time which is from 2005-2010.

In addition, all the respondents were very particular with the price factor because they mostly bought flight tickets from airlines offering lowest prices and without any hidden charges. In terms of experience using websites, most participants make comparisons between all the airlines because in the AirAsia website cases, they felt that this company had wanted to trick the customers through the website in terms of information consistency, the website design was not easy to use, time constraint while making online purchase, and also bad experience during web check-in as they had to re-fill in the passenger details multiple times.

One of the participants, who was an international customer, expressed frustration over the web check-in service provided by AirAsia because he said that this company had never acknowledged his web check-in and he had to recheck-in when he arrived at the airport. He found that this method wasted his time and he labelled AirAsia as discriminating customers because he was an international customer. Meanwhile, in receiving notifications from airlines, most of the participants had been dissatisfied. Based on their experience, they found that most of the airlines will give a late notification for the customers if there is any flight schedule changes. This issue will affect the customer's initial planning on their travel. As for the trust factor, most of the participants trusted the flight e-ticketing system in Malaysia in terms of e-payment, privacy, or any other factors. Nonetheless, only one participant admitted that he never trusted a system that asked him to give a CVV number when doing 
an e-payment using a credit card because he felt uncomfortable sharing his CVV credit card number on the website.

As for the holiday packages offered by the airlines, none of the participants had purchased it because they found that the holiday package prices were higher compared to the prices offered by travel agents. If they had wanted to go for a holiday, most of them preferred booking a hotel or any other accommodation separately from flight tickets. Lastly, in terms of culture and religion issues, most participants expressed unhappiness towards the cabin crew.

They said that most cabin crews were impolite and did not use proper Bahasa Malaysia. In fact, one participant claimed that the reason why he did not buy any food on board was because the airlines never displayed the "halal" logo on their food, which is rather an important issue to Muslim customers. The interview discussion also captured that most of the respondents were dissatisfied with several online service in the airline e-ticketing system in Malaysia. In general, the reasons why participants keep repeating flight ticket purchase with the same airlines had been due to the price factor, direct route, and e-payment services.

In the recommendation section, most participants want airlines in Malaysia to improve on several services on the websites as well as beyond websites to meet their needs and satisfaction. The participant said that the airlines need to explain clearly about promotions, improve the services in terms of explaining the actual prices, provide detailed information on websites, and the seats need to be arranged based on booking number, not randomly.

\section{Conclusion}

This research provides the thorough understanding of how most of airlines in Malaysia applies factors in order to determine the level of satisfaction towards their companies. This is can be concluded that most of airlines in Malaysia now choose to use an internet as a platform to them to sell 
their flight ticket to the customers. From the finding received, most of participants are not really happy with the electronic services like website check-in that provided by airlines companies. Perhaps, this finding will help the company to improve their services and business skill in future in order to meet their customer's needs.

\section{References}

D.Will, (2016) “Information Technology's Strategy Impact on the Air Travel Service Industry”. The journal of Information \& Management for American Airline, pp. 24-56.

Fjermested, J and Romano,N.C. Jr (2003) Electronic Customer Relationship Management: Revisiting the General Principles of Usability and ResistanceAn Integrative Implementation Framework, Business Process Management Journal, 9(5), 572-579.

J. Ng, Ainin Sulaiman and M.Suhana, "E-Ticketing Is One of The New Approach Based On Customer Perspective”. Journal of Social Science, pp.144-157.

N. K. Malhotra, "Chapter 5 QUESTIONNAIRE DESIGN AND SCALE DEVELOPMENT What Is a Questionnaire? Why Is a Questionnaire Important? What Information Is Needed? How Should Individual Questions Be Framed?", n.d, pp.176-202.

P. Randiwela, (2010) “E-CRM for Sri Lankan Tourism Industry,”, pp. 700710.

Rafidah, M.R (2014). Modeling User Experience on AirAsia Airline eTicketing As Online Services. 1-19. 
Rahim, A.G., Ignatius, I.U., \& Adeoti, O.E. (2012). Is Customer Satisfaction an Indicator of Customer Loyalty? Australian Journal of Business and Management Research. 2(7), 14-20

Romano,N.C. Jr and Fjermested, J (2003) Electronic Customer Relationship Management: Revisiting the General Principles of Usability and ResistanceAn Integrative Implementation Framework, Business Process Management Journal, 9(5), 572-579.

S. Mohezar and A. Sulaiman, "e-ticketing as a new way of buying tickets: Malaysian Perceptions", 2010, pp.149-157.

T. Alhaiou, Zahir Irani, and Maged Ali (2011), "The Relationship between eCRM Implementation and E-Loyalty at Different Adoptions Stages of Transaction Cycle : A conceptual Framework and Hypothesis”. European and Mediterranean Conference on Information System 